\title{
Avaliação de restaurante universitário por meio do regulamento técnico de boas práticas para serviços de alimentação
}

\section{University restaurant evaluation through the best practice technical regulations for food services}

\author{
Rebeca Morais Silva Santos ${ }^{1}$, Deyzi Santos Gouveia ${ }^{2}$, Ana Paula Trindade Rocha ${ }^{2}$, Willame Mendes da Silva ${ }^{2}$, Analha Dyalla \\ Feitosa Lins ${ }^{3}$
}

\begin{abstract}
Resumo: Diante dos desconfortos ocorridos no Restaurante Universitário da Universidade Federal de Campina Grande Campus I, relacionados à qualidade das refeições servidas diariamente, notou-se a necessidade da implantação de um programa de verificação e atualização das boas práticas de manipulação de alimentos. Objetivou-se a avaliação das práticas de manipulação alimentar e das condições das instalações higiênico-sanitárias do restaurante, com posterior treinamento dos funcionários, para melhoramento da qualidade e segurança dos alimentos servidos. A verificação deu-se pela aplicação do check-list disposto na resolução RDC no 216/2004 da ANVISA. O Restaurante Universitário apresentou dos 123 questionamentos realizados, $37,3 \%$ de conformidades, $43 \%$ de não conformidades, e os demais quesitos foram preenchidos com a opção NA (Não se aplica) ou não puderam ser preenchidos por falta de acesso às informações necessárias. Conforme a classificação pela Categorização dos Serviços de Alimentação da ANVISA, o estabelecimento foi no Grupo 4, com nota 605,38. O Restaurante Universitário oferecia riscos de ocorrências de Doenças Transmitidas por Alimentos, devido à grande quantidade de itens avaliados fora da conformidade. Sugeriu-se treinamento contínuo aos funcionários e a disponibilização de um profissional capacitado na área, para supervisão e treinamento dos manipuladores de alimentos.
\end{abstract}

Palavras-chaves: Higiene. Manipulação alimentar. Doenças Transmitidas por Alimentos. Boas Práticas de Manipulação de Alimentos.

\begin{abstract}
Before with the discomforts occurred in the University Restaurant of the Federal University of Campina Grande Campus I, related to the quality of the meals served daily, noted the need to implement a verification program and updating of good food handling practices. The objective of the assessment of food handling practices and conditions of hygiene and sanitary facilities restaurant, with subsequent training of employees to improve the quality and safety of food served. The verification was due to the implementation of the checklist provisions of resolution RDC $n^{\circ}$. 216/2004 of ANVISA. The University Restaurant presented the 123 inquiries made, 37.3\% of compliance, $43 \%$ of non-compliance, and other questions were filled with the NA option (Not applicable) or could not be completed due to lack of access to necessary information. As ranked by the categorization of ANVISA Food services, the property was in Group 4, with score 605.38. The University Restaurant offering risk Transmitted Disease occurrences for food due to the large amount of items evaluated out of compliance. It was suggested ongoing training to employees and the availability of a skilled professional in the area for supervision and training of food handler.
\end{abstract}

Key words: Hygiene. Food handling. Foodborne Diseases. Good Food Handling Practices.

\footnotetext{
*Autor para correspondência

Recebido para publicação em 05/02/2015; aprovado em 27/02/2015

${ }^{1}$ Graduanda em Engenharia de Alimentos, Universidade Federal de Campina Grande; Campina Grande; (83)8853-6003; rebecamoraiscg@ gmail.com

${ }^{2}$ Professora Eng. de Alimentos Universidade Federal de Campina Grande, E-mail: deyzi.gouveia@ufcg.edu.br

${ }^{2}$ Professora Eng. de Alimentos Universidade Federal de Campina Grande, E-mail: ana.trindade@ufcg.edu.br

${ }^{3}$ Mestrando em Sistemas Agroindustriais (PPGSA)- Universidade federal de Campina Grande, E-mail: willmendes2013@hotmail.com

${ }^{4}$ Mestranda Eng. Agrícola Universidade federal de Campina Grande, E-mail: dyallalins@gmail.com
} 


\section{INTRODUÇÃO}

O Programa Restaurante Universitário (RU) é o meio pelo qual a Universidade Federal de Campina Grande oferece refeições (almoço e jantar) gratuitas, diariamente, aos estudantes carentes matriculados na instituição (ASCOM UFCG, 2011). Porém, nos últimos dois anos, qualquer aluno matriculado, que deseja se alimentar tem acesso a tais refeições, o que causa o aumento da quantidade de alimentos preparados e manipulados.

Com este aumento, notou-se a queda da qualidade dos alimentos servidos. As reclamações ocorridas foram em relação à carnes servidas praticamente cruas, à alimentos mal preparados, à gosto e aparência, falta de higiene, entre outros.

Durante as etapas de produção dos alimentos, existem diversas condições que podem levar à introdução de microrganismos patogênicos nas refeições, o que pode comprometer a qualidade e a segurança alimentar. Alimentos contaminados por microrganismos ou por agentes químicos causam DTA's (Doenças Transmitidas por Alimentos) que oferecem riscos à saúde do consumidor, podendo causar até a morte do indivíduo.

A preparação e a manipulação de alimentos exigem cuidados com sua execução, quanto maior a quantidade de alimentos a serem preparados, maior deverá ser a atenção dos manipuladores com tais cuidados.

Em vista da vulnerabilidade dos alimentos às contaminações e dos riscos que os alimentos contaminados oferecem à saúde do consumidor, a ANVISA (Agência Nacional de Vigilância Sanitária), criou normas que, postas em prática durante a manipulação dos alimentos, garantem a segurança e qualidade alimentar.

Diante das decorrentes reclamações dos usuários do Restaurante Universitário da UFCG, em relação à qualidade da alimentação servida diariamente, notou-se a necessidade da verificação da conformidade dos serviços prestados pelo R.U., com as normas exigidas pela ANVISA. Desta forma, esse trabalho objetivou a implantação de um programa de verificação e atualização de tais normas, com o objetivo de avaliar as práticas de manipulação alimentar e das instalações higiênico-sanitárias do restaurante, e posteriormente, oferecer treinamento aos funcionários visando à eliminação dos riscos de doenças transmitidas por alimentos, e melhoramento da qualidade e segurança dos alimentos servidos.

\section{MATERIAL E MÉTODOS}

Foram avaliadas as condições higiênico-sanitárias, as práticas de manipulação alimentar, e a aplicação das normas descritas na legislação, no Restaurante Universitário da Universidade Federal de Campina Grande, campus I, por meio da aplicação da check-list disposta na Resolução RDC $n^{\circ}$ 216/2004 da ANVISA (Agência Nacional de Vigilância Sanitária), a qual descreve normas relacionadas a boas práticas para serviços de alimentação, durante visitas ao restaurante, com o auxílio e o acompanhamento de funcionários presentes durante o horário das visitas.

Os itens avaliados foram dispostos na seguinte ordem: Instalações, edificações, equipamentos, móveis e utensílios (24 quesitos); Higienização de instalações, equipamentos, móveis e utensílios (13 quesitos); Controle integrado de vetores e pragas (05 quesitos); Abastecimento de água (09 quesitos); Manejo dos resíduos (04 quesitos); Manipuladores (14 quesitos); Matérias-prima, ingredientes e embalagens (13 quesitos); Preparo do alimento (25 quesitos); Armazenamento e transporte do alimento preparado (05 quesitos); Exposição ao consumo do alimento preparado (07 quesitos); Documentação e registro (04 quesitos);

As opções de resposta para o preenchimento foram: "Sim" - usado quando o resultado do questionamento fosse positivo, "Não" - usado quando o resultado fosse negativo, e "NA" (não se aplica) para itens não aplicáveis.

$\mathrm{O}$ treinamento dado aos funcionários foi elaborado e aplicado com base na RDC $\mathrm{n}^{\circ} 216$, de acordo com a ANVISA (2004)

A classificação do Restaurante Universitário foi realizada conforme uma adaptação da Cartilha de Categorização dos Serviços de Alimentação (ANVISA, 2013), de maneira que os itens avaliados foram designados como eliminatórios, pontuados e classificatórios. O estabelecimento seria pontuado em caso de não cumprimento dos itens pontuados, de forma que, quanto maior a nota, maior o número de não conformidades encontradas.

Para a categorização, considerou-se ainda o Índice de Impacto (IIp) associado a relevância do item avaliado, na prevenção de uma doença transmissível por alimentos, de maneira que quanto maior a relevância do item, maior o IIp. A nota final do estabelecimento é obtida pela soma da pontuação de cada item, que dar-se pela multiplicação do IIp pela Carga Fatorial (CF) (ANVISA, 2013) .

\section{RESULTADOS E DISCUSSÃO}

Através da avaliação realizada no Restaurante Universitário a partir do check-list, obtivemos os seguintes resultados: dos 123 questionamentos realizados, foram obtidos $37,3 \%$ de conformidades, $43 \%$ de não conformidades, $17 \%$ dos quesitos foram preenchidos com a opção NA (Não se aplica), e 2,7\% dos questionamentos não puderam ser preenchidos por falta de acesso às informações necessárias (Gráfico 1).

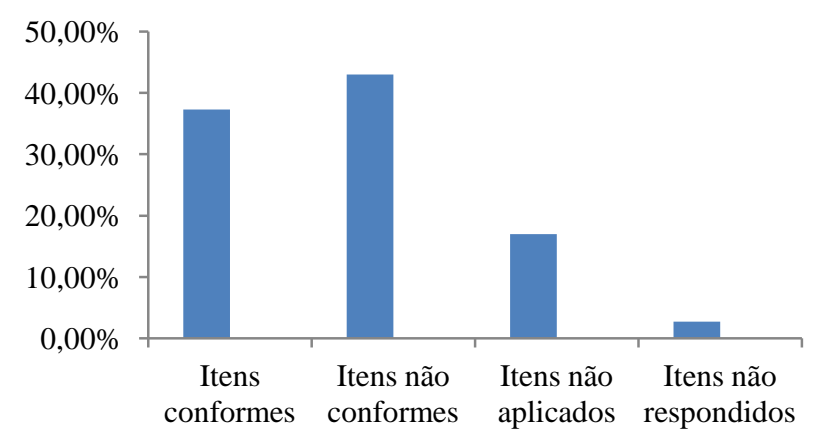

Gráfico 1: Resultados obtidos pela aplicação do check-list.

Dos 24 questionamentos sobre instalações, edificações, equipamentos, móveis e utensílios, obtiveram-se os seguintes resultados: $66,6 \%$ de itens em não conformidade e $29,1 \%$ de itens em conformidade com a legislação vigente. Apenas um item foi marcado como "Não se aplica", correspondendo a 4,1\% dos questionamentos (Gráfico 2). 


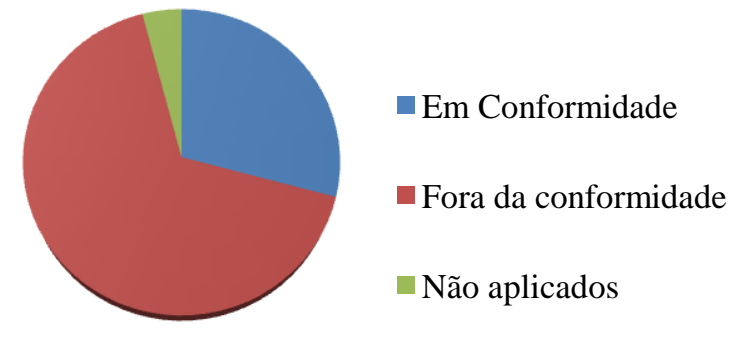

Gráfico 2.: Resultados obtidos pela avaliação das instalações, edificações, equipamentos, móveis e utensílios.

Nestes quesitos, o restaurante apresentou presença de agentes contaminantes e focos de insalubridade como esgoto a céu aberto, presença de lixo exposto, animais e automóveis, próximos a entrada principal que dá acesso ao setor de produção (Figura 1). O acesso a área interna do restaurante não é independente, sendo aberta e sem controle de entrada de pessoas que não trabalham no setor, e os acessos aos banheiros e vestiários são interligados ao setor de produção, de maneira que a porta que separa os setores é mantida sempre aberta.

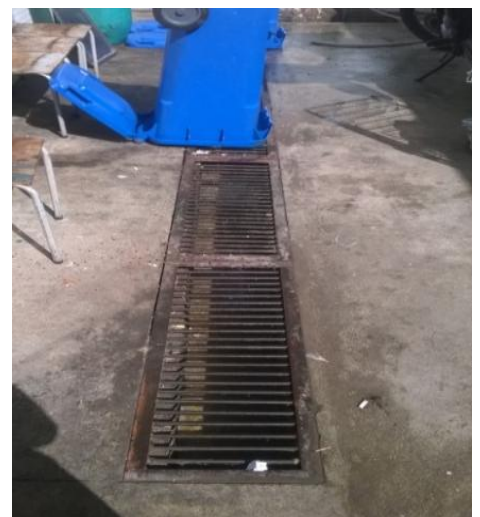

Figura 1: Esgoto a céu aberto na entrada principal.

As portas que o Restaurante dispõe, não possuem fechamento automático, e as aberturas externas não são providas de telas milimetradas: existem duas janelas pequenas de vidro que permanecem sempre fechadas, porém a porta principal é mantida aberta, e na área dos vestiários contém uma janela aberta e extensa que permite a entrada de agentes contaminantes. Os ângulos entre paredes e pisos não são abaulados. $\mathrm{Na}$ área de produção, existe uma caixa de esgoto que oferece grande risco de contaminação aos alimentos. A iluminação do Restaurante é adequada, porém não existe nenhuma proteção contra explosão e quedas acidentais.

Apesar da porta principal manter-se sempre aberta, a área interna não possui ventilação adequada, fazendo com que o ambiente esteja sempre desconfortável para os funcionários, e vulnerável a presença de agente contaminantes suspensos no ar. O restaurante dispõe de duas unidades de exaustores, responsáveis pela expulsão do ar quente proveniente das caldeiras, porém, não existe nenhum tipo equipamento de climatização como ar condicionado. Existe um ventilador de mesa que é mantido próximo aos balcões onde os alimentos são preparados, em justificativa que o ventilador do teto não funciona, porém, a presença desde eletrodoméstico não está em conformidade com a resolução RDC n ${ }^{\circ}$ 275/2002 da
ANVISA, que proíbe a presença de itens não comuns ao setor de produção de alimentos.

Os banheiros e os vestiários são desorganizados, com armário e instalações mal conservados, e não são providos de portas externas com acionamento automático, lavatórios adequados, nem materiais de higiene em geral.

A área de manipulação não possui lavatórios exclusivos para higienização das mãos, existe somente um lavatório dentro do setor de produção para uso geral, e outro mais afastado para lavagem de panelas e caldeirões. Estes lavatórios são providos apenas de detergente e/ou sabão em barra. Os equipamentos, móveis e utensílios que entram em contato direto com alimentos, em sua maioria, são de material liso (Figura 2), porém, é utilizado a colher de pau para realização das misturas nas caldeiras, o que contradiz as exigências da resolução RDC n ${ }^{\circ}$ 216/2004 da ANVISA, a qual exige que utilização de utensílios de superfícies de material liso para que não ofereçam risco de contaminação do alimento.

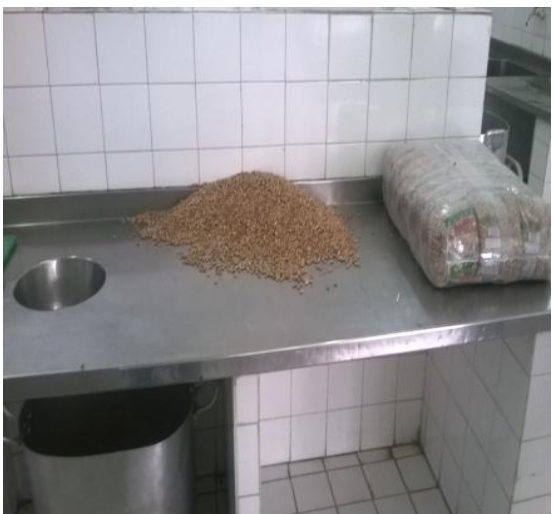

Figura 2: Bancada em material liso e fácil de ser higienizado.

Dos 13 questionamentos sobre higienização de instalações, edificações, equipamentos, móveis e utensílios, obtiveram-se os seguintes resultados: $23 \%$ de itens em não conformidade, e $77 \%$ de itens em conformidade com a legislação vigente (Gráfico 3).

A higienização do setor de produção é realizada após a conclusão de cada refeição, ou seja, depois da produção do almoço e após a produção do jantar. Porém, não é realizada higienização antes do início das atividades produtivas, e, durante a produção, o setor não é mantido higienizado, contendo a presença de lixo no chão e em cima das bancadas, chão molhado com água misturada com sangue proveniente do descongelamento incorreto de carnes.

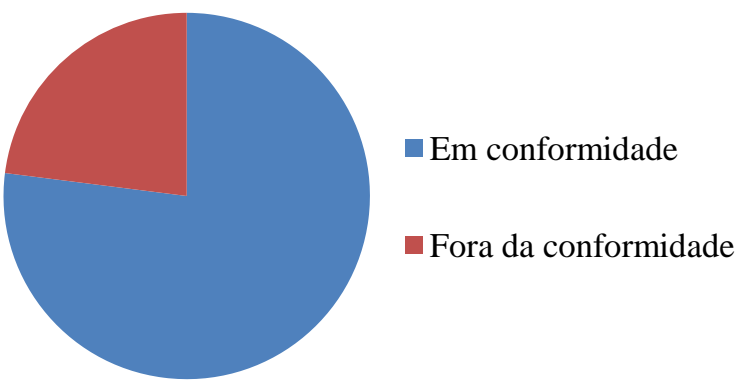

Gráfico 3: Resultados obtidos pela avaliação da higiene das instalações, edificações, móveis e utensílios.

Os funcionários responsáveis pela higienização das instalações sanitárias não são exclusivamente designados para 
esta função, pois existe um revezamento de funções, em vista que o número de funcionários é insuficiente, além de não serem comprovadamente capacitados, e não utilizarem uniformes apropriados e diferenciados daqueles utilizados na manipulação de alimentos.

Sobre o controle integrado de pragas, dos 05 questionamentos, foi obtido os seguintes resultados: $80 \%$ de itens em conformidade com a legislação vigente, e $20 \%$ em não conformidade (Gráfico 4).

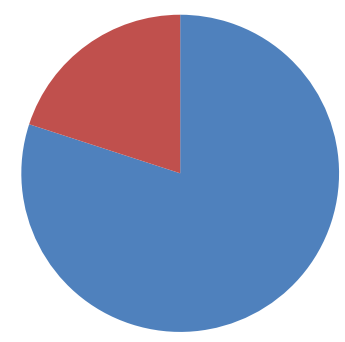

Em conformidade

- Fora da conformidade

Gráfico 4: Resultados obtidos pela avaliação do controle integrado de pragas.

Durante as visitas, não foi encontrado a presença de vetores, pragas urbanas e seus vestígios, apesar de não ter sido verificado um conjunto de ações preventivas para evitar o acesso de vetores e pragas. Segundo informações prestadas pela direção do Restaurante Universitário e funcionários presentes no momento das visitas, é realizada dedetização periódica por uma empresa especializada e licenciada, porém não tivemos acesso a registros destas ações.

Para o abastecimento de água foi verificado os seguintes resultados: $22,2 \%$ de itens em conformidade com a legislação vigente, e 44,4\% dos itens foram preenchidos com a opção "Não se aplica. Não foram preenchidos 33,3\% dos questionamentos deste item, pois não foi possível ter acesso ao reservatório de água do Restaurante (Gráfico 5).

As atividades de produção de alimentos são realizadas somente com a utilização de água potável fornecida pela rede pública, e não existe utilização de fonte alternativa de água. O Restaurante possui um reservatório de água feito de cimento e mantido tampado, localizado acima do teto do estabelecimento, porém não foi possível ter acesso ao seu interior.

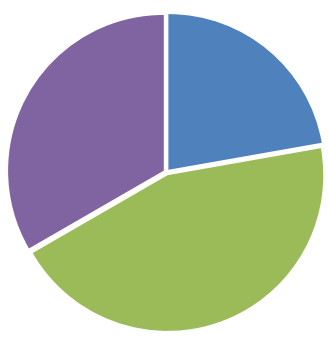

Em conformidade

- Fora da conformidade

Não aplicados

- Não preenchidos

Gráfico 5: Resultados obtidos pela avaliação do abastecimento de água.

Conforme informações da direção, o reservatório de água passa por higienização periódica, mas não tivemos acesso aos registros destas ações e ao período de tempo que a higienização é realizada.
Dos 04 questionamentos sobre manejo de resíduos, obtiveram-se os seguintes resultados: $75 \%$ de itens em não conformidade, e $25 \%$ de itens em conformidade com a legislação vigente (Gráfico 6).

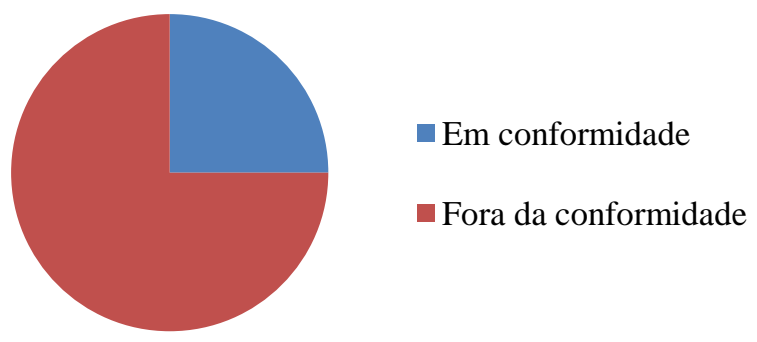

Gráfico 6: Resultados obtidos pela avaliação do manejo de resíduos.

O Restaurante dispõe de coletores de lixo com acionamento das tampas sem contato manual em quantidade insuficiente, provocando o acúmulo de resíduos no setor de produção durante o expediente. Como a quantidade de lixo é maior do que a quantidade de coletores, estes são mantidos abertos e com o lixo transbordando. O lixo é acumulado em cima das bancadas, pias e no chão durante todo um expediente, e só é retirado ao final da preparação de cada refeição. Os coletores com lixo são mantidos do lado de fora do Restaurante, próximo à entrada principal, e é retirado ao final de todos os dias.

Dos 14 questionamentos sobre manipuladores, obtiveram-se os seguintes resultados: $64,2 \%$ de itens em não conformidade, $28,5 \%$ de itens em conformidade com a legislação vigente, e 7,14\% dos itens foram preenchidos com a opção "Não se aplica" (Gráfico 7).

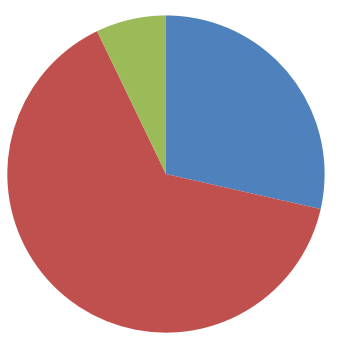

Em conformidade

Fora da conformidade

Não aplicados

Gráfico 7: Resultados obtidos pela avaliação dos manipuladores

Os manipuladores apresentaram-se asseados, mas não completamente: todos vestiam camisa e calça jeans, todos os homens usavam bonés e todas as mulheres utilizavam toucas; Verificou-se a utilização de botas, mas nem todas na cor branca, e algumas mulheres utilizavam sapatilhas; Todos os manipuladores com jaleco branco e os responsáveis pelo corte de carnes com luva de aço na mão que apóia a carne para o corte.

Os uniformes apresentaram-se conservados e limpos, porém foi verificado o uso de adornos como relógios, brincos, entre outros. Os objetos pessoais dos funcionários eram guardados em local separado, mas não de maneira adequada e organizada.

Os manipuladores não possuíam carteira de saúde e nenhum registro de realização de exames periódicos. 
Aparentemente, apresentavam-se em bom estado de saúde, em sua maioria, sem lesões ou enfermidades que pudessem comprometer o preparo do alimento. Apenas um funcionário informou que estava se sentindo mal, e que geralmente não são afastados ou mudados de setor quando se encontram em situação de enfermidade.

Verificou-se uma preocupação com a lavagem das mãos por parte dos funcionários, porém, o restaurante não dispõe de todos os materiais necessários para a lavagem e assepsia das mãos, sendo utilizado apenas detergente ou sabão em barra. Não foi verificada a presença de cartazes de orientação sobre a correta lavagem e antisepsia das mãos ou outros hábitos de higiene, exceto os cartazes relacionados com a proibição do uso de celular e obrigatoriedade do uso da touca dentro da área de produção, apesar de que estas exigências não fossem cumpridas.

Os manipuladores de alimentos não são comprovadamente capacitados para esta função, e não existe um supervisor capacitado na área de boas práticas de fabricação de alimentos.

$\mathrm{Na}$ avaliação das matérias-primas, dos ingredientes e das embalagens, foram obtidos os seguintes resultados: dos 13 questionamentos, 46,1\% encontravam-se em conformidade e o restante $53,8 \%$ em não conformidade com as exigências da legislação vigente (Gráfico 8).

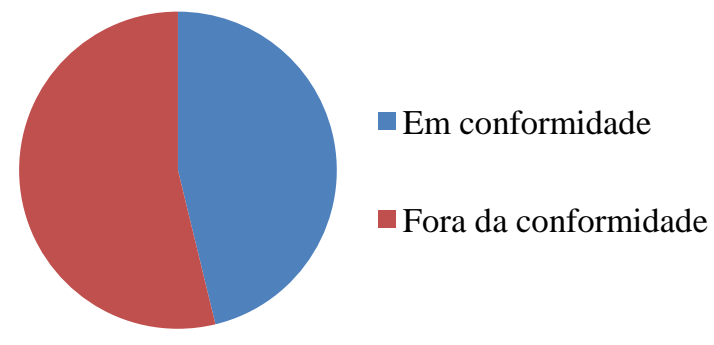

Gráfico 8: Resultados obtidos pela avaliação das matériasprimas, ingredientes e embalagens.

As matérias-primas utilizadas no Restaurante eram transportadas em condições adequadas de higiene e conservação, as embalagens sempre íntegras e, na recepção, era realizada uma inspeção para verificação da integridade das embalagens e a validade dos produtos. Em caso de produtos com prazo de validade vencido, era feita a separação de tais produtos para que houvesse a devolução ou destinação adequada. No caso de produtos que dispensavam a obrigatoriedade da indicação do prazo de validade, era observada a ordem de entrada do mesmo, para que os mais antigos fossem consumidos primeiro. E, os produtos que necessitavam de verificação de temperatura, não recebiam a atenção adequada, pois o termômetro que o restaurante dispunha encontrava-se sem funcionar e não foi apresentado no momento das visitas. A única inspeção feita em tais produtos era a verificação da data de validade.

A área destinada à recepção e armazenamento dos produtos comprados pelo Restaurante é independente da área de produção, porém, é aberta, de tamanho insuficiente e disposta sem organização e sem identificação, de maneira que os produtos não perecíveis, como lotes de cereais, encontravam-se muito próximo de produtos perecíveis; frutas encontravam-se no chão; potes de margarina abertos e sem refrigeração; e presença de objetos não comuns ao setor, como vassouras, aventais, panos de limpeza, etc (Figura 5). Os paletes utilizados para o armazenamento dos alimentos não eram todos de material liso e lavável, sendo alguns de madeira (Figura 4).

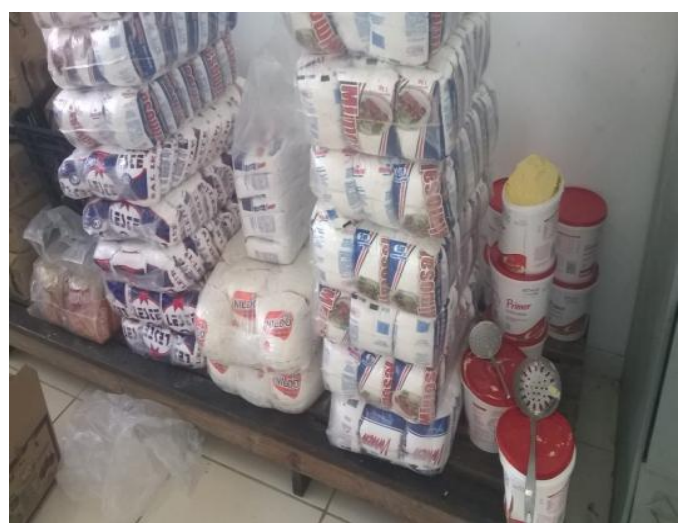

Figura 3: Produtos perecíveis mal acondicionados.

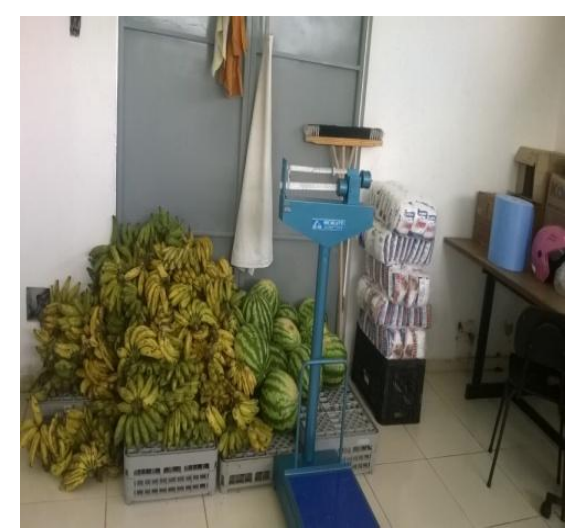

Figura 4: Presença de objetos não comuns ao setor.

$\mathrm{Na}$ avaliação do preparo do alimento, dos 25 quesitos foram obtidos os seguintes resultados: $28 \% \mathrm{em}$ conformidade, $40 \%$ em não conformidade, e $32 \%$ dos quesitos foram preenchidos com a opção "Não se aplica" (Gráfico 9).

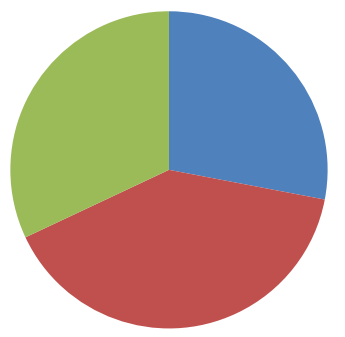

Em conformidade

Fora da conformidade

Não aplicados

Gráfico 9: Resultados obtidos pela avaliação do preparo do alimento

O quantitativo de funcionários não se apresentava em quantidade compatível com o volume e necessidade das preparações, mas, mesmo com isso, as matérias-primas, os ingredientes e as embalagens utilizados no preparo dos alimentos encontravam-se em condições adequadas de higiene, exceto os produtos perecíveis (carnes) que não se encontravam expostos em temperatura adequada, sendo 
descongelados em temperatura ambiente e expostos muito próximos ao chão (Figura 5).

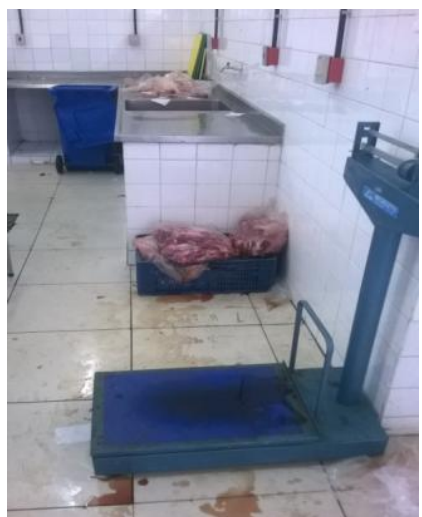

Figura 5: Descongelamento de carnes em temperatura ambiente (inadequado) em local incorreto.

Durante o preparo, evitava-se o contato direito ou indireto entre os alimentos crus, semi-preparados e prontos para consumo, para que não houvesse contaminação cruzada. Para o preparo dos alimentos consumidos crus, verificou-se a realização de um processo de higienização a fim de reduzir a contaminação superficial dos frutos e das hortaliças, com a utilização de produtos regularizados pelo Ministério da Saúde e aplicados de maneira correta, conforme indicação do fabricante. Os funcionários que manipulam os alimentos crus realizam a lavagem das mãos, porém não de maneira adequada em vista da falta dos materiais de higiene necessários. Já em relação aos alimentos providos de embalagens, não se verificou a realização de limpeza adequada de suas embalagens.

O tratamento térmico (cozimento) dos alimentos garante que todo o alimento atinja a temperatura indicada (no mínimo $70^{\circ} \mathrm{C}$ ), e após o cozimento, os alimentos preparados são mantidos em condição de tempo e de temperatura que não favoreçam a multiplicação microbiana: assim que eram preparados, dava-se início a exposição para consumo, de maneira que os alimentos quentes eram expostos em bandejas submetidas a banho-maria, porém, não foi verificado nenhum monitoramento da temperatura da água utilizada no banhomaria.

A avaliação dos 05 itens relacionados ao armazenamento e transporte do alimento preparado não foram considerados, pois $100 \%$ dos itens avaliados foram preenchidos com a opção "Não se aplica", com a justificativa de que o Restaurante Universitário não faz armazenamento e transporte do alimento preparado, pois a quantidade preparada diariamente é consumida, em sua totalidade, no próprio restaurante.

A avaliação da exposição ao consumo do alimento preparado obteve os seguintes resultados: dos 07 quesitos, $57,1 \%$ estavam em conformidade, $14,2 \%$ em não conformidade com a legislação vigente, e $28,5 \%$ foram preenchidos com a opção "Não se aplica" (Gráfico 10).

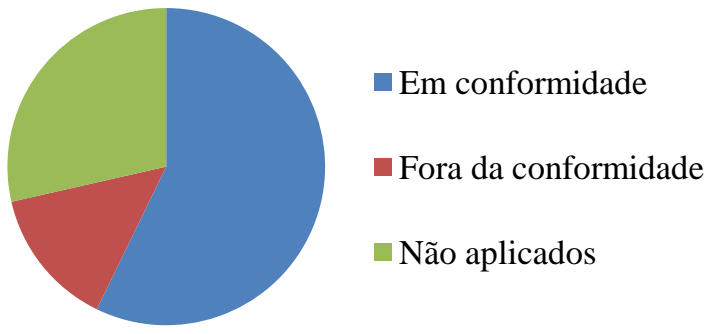

Gráfico 10: Resultados obtidos pela avaliação da exposição dos alimentos preparados para consumo.

A bancada de exposição do alimento preparado apresentava-se disposta de maneira organizada, linear e higiênica, porém o chão estava sempre molhado oferecendo risco de proliferação de microrganismos e de acidentes. A área do refeitório estava disposta de maneira organizada, mas não notificou-se a presença de funcionários responsáveis pela limpeza do local durante a consumação dos alimentos, o que permitia a presença de sujidades nas superfícies da mesa, as quais atraíam vetores como moscas. O refeitório dispunha de janelas que eram mantidas abertas, as quais permitiam o acesso de animais.

O Restaurante não dispunha de área suficiente para a quantidade de pessoas que tinham acesso ao refeitório, de maneira que algumas pessoas tinham que esperar outras terminarem sua refeição, para que pudessem se sentar. Os lavatórios existentes na área de consumação não apresentavam condições adequadas de higiene e manutenção, com vazamentos e desprovidas de materiais de higiene necessários.

Os equipamentos de exposição dos alimentos preparados não dispunham de barreira de proteção que previnam a contaminação do mesmo em decorrência da proximidade ou da ação do consumidor e de outras fontes.

Os utensílios utilizados na consumação do alimento não eram descartáveis, mas passavam por adequado processo de higienização e assepsia, porém alguns talheres se encontravam em estado de má conservação, sendo necessária a substituição de tais itens.

Em relação à avaliação da documentação e dos registros do Restaurante, apenas 25\% dos 04 itens avaliados, apresentaram-se em conformidade (Gráfico 11).

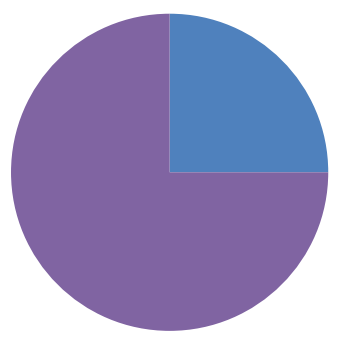

Em conformidade

Fora da conformidade

- Não aplicados

- Não preenchidos

Gráfico 11: Resultados obtidos pela avaliação da documentação e dos registros.

Verificou-se a disposição de POP's das operações realizadas com frequência, porém esse material não foi implementado. Não se teve acesso a nenhum tipo de registro relacionado a qualquer operação realizada no restaurante.Conforme a classificação pela 
CATEGORIZAÇÃO DOS SERVIÇOS DE ALIMENTAÇÃO da ANVISA, o Restaurante Universitário obteve nota 605,38, sendo classificado no Grupo 4

\section{CONCLUSÕES}

O Restaurante Universitário oferecia riscos de ocorrências de DTA's, devido à grande quantidade de itens fora da conformidade, os quais exigem atenção, tanto para as instalações higiênico-sanitárias quanto para a manipulação de alimentos.

Através de uma verificação feita após a realização do treinamento, notou-se uma maior preocupação e cuidado, por parte dos manipuladores, com a realização dos procedimentos de preparo e manipulação dos alimentos, seja com higiene pessoal, lavagem correta e periódica das mãos, entre outros itens avaliados.

Assim, sugere-se um treinamento contínuo para os funcionários e a disponibilidade de um profissional capacitado na área, que seja responsável por supervisionar os procedimentos de manipulação e preparo dos alimentos, por realizar o treinamento contínuo dos manipuladores, e por implantar o Programa de Boas Práticas de Fabricação de Alimentos e os Procedimentos Operacionais Padrões.

\section{REFERÊNCIAS BIBLIOGRÁFICAS}

ANVISA - Agência Nacional de Vigilância Sanitária. Categorização dos serviços de alimentação: Material de apoio para serviços de alimentação. Brasília, 2013. Disponível em: http://portal.anvisa.gov.br/wps/wcm/connect/de113f804f e4bde9957efdece 77a031c/categoriza\%C3\%A7\%C3\%A 3o+baixa.pdf?MOD=AJPERES. Acesso em: 25 de Fevereiro de 2014.

ANVISA - Agência Nacional de Vigilância Sanitária. Categorização dos serviços de alimentação: Elaboração e validação da lista de avaliação. Brasília, $2013 . \quad$ Disponível em: http://www.anvisa.gov.br/hotsite/hotsite_categorizacao/ documentos/Resumo_executivo_final.pdf. Acesso em 09 de fevereiro de 2015.
ANVISA - Agência Nacional de Vigilância Sanitária. Lista de Avaliação dos Serviços de Alimentação. 2013. Disponível em: http://www.anvisa.gov.br/hotsite/hotsite_categorizacao/ metodos_categorias.html. Acesso em 09 de fevereiro de 2015.

ANVISA - Agência Nacional de Vigilância Sanitária. Resolução - RDC No 216, de 15 de setembro de 2004. Dispõe Sobre Regulamento Técnico de Boas Práticas para Serviços de Alimentação. Disponível em: <http://portal.anvisa.gov.br/wps/wcm/connect/4a3b6800 40bf8cdd8e5dbf1b0133649b/RESOLU\%C3\%87\%C3\% $83 \mathrm{O}-$

RDC+N+216+DE+15+DE+SETEMBRO+DE+2004.pdf ?MOD=AJPERES $>$. Acesso em 23 de Fevereiro de 2014.

ANVISA - Agência Nacional de Vigilância Sanitária. Resolução - RDC No 275, de 21 de outubro de 2002. Dispõe sobre o Regulamento Técnico de Procedimentos Operacionais Padronizados aplicados aos Estabelecimentos Produtores/Industrializadores de Alimentos e a Lista de Verificação das Boas Práticas de Fabricação em Estabelecimentos Produtores/Industrializadores de Alimentos. Disponível em: < http://portal.anvisa.gov.br/wps/wcm/connect/dcf7a9004 74576fa84cfd43fbc4c6735/RDC+N\%C2\%BA+275,+D $\mathrm{E}+21+\mathrm{DE}+\mathrm{OUTUBRO}+\mathrm{DE}+2002 . \mathrm{pdf}$ ?MOD=AJPERE $\mathrm{S}>$.

ASCOM - UFCG - Assessoria de Comunicação da Universidade Federal de Campina Grande - UFCG. Restaurante Universitário garante permanência de alunos na UFCG. Campina Grande - PB. 2011. Disponível em: http://www.ufcg.edu.br/prt_ufcg/assessoria_imprensa/m ostra_noticia.php?codigo $=11751$. Acesso em 25 de Fevereiro de 2014. 